\title{
Post-hyperventilation apnoea in patients with brain damage
}

\author{
SHEILA JENNETT, KAREN ASHBRIDGE ${ }^{1}$, AND J. B. NORTH ${ }^{2}$ \\ From the Institute of Neurological Sciences, and Departments of Neurosurgery \\ and of Physiology, University of Glasgow, Scotland
}

SYNOPSIS A study of 100 subjects has confirmed that brief voluntary hyperventilation commonly causes apnoea in patients with supramedullary lesions, but not in healthy people. Apnoea was related to drowsiness rather than to the extent of the lesion; it was unrelated to the measured reduction in end-tidal carbon dioxide tension.

Haldane and Priestley (1905) and Douglas and Haldane (1909) demonstrated by a series of experiments, mainly on themselves, that a period of apnoea followed hyperventilation; they attributed this interruption of breathing to a lowering of the carbon dioxide tension $\left(\mathrm{PCO}_{2}\right)$ in the respiratory centre to a value below the threshold for activity. Boothby (1912) failed to confirm the phenomenon, while Mills (1946) demonstrated hyperpnoea after forced breathing in 25 out of 35 subjects studied, and complete absence of apnoea in 12 of 16 subjects in a further study (personal communication). Fink (1961) likewise could not elicit post-hyperventilation apnoea in 13 normal conscious subjects; he suggested that maintenance of normal respiratory rhythm in the wakeful state is due to a non-chemical stimulus which acts in the absence of metabolic stimuli and can be damped by sleep, anaesthesia, sedation, or neurological dysfunction.

Plum et al. (1962) found post-hyperventilation apnoea of more than $12 \mathrm{sec}$ duration to be so unusual in normal subjects, and in patients with unilateral brain damage, that they suggested that it could be employed as a sign of bilateral cerebral damage. Their test involved voluntary hyperventilation by the patient in the form of five deep breaths. Only those tests in which the patient succeeded in lowering the end-tidal $\mathrm{PCO}_{2}$ by at least 6 torr were included in the study. These

1 Student vacation scholar supported by grant to S.J. from Christine Murrell Award of the Medical Womens' Federation.

2 Commonwealth Medical Fellow in Neurosurgery. authors observed post-hyperventilation apnoea in more than $90 \%$ of patients with bilateral supramedullary brain disease, but in very few patients with unilateral disorders; they con $\tilde{N}_{\infty}$ cluded that the non-chemical respiratory drive in $\infty$ such patients must be impaired, leaving the्ष respiratory centre vulnerable to changes in the $\mathrm{PCO}_{2}$ of the arterial blood. They regarded sus ceptibility to prolonged (more than 12 seco o apnoea as a useful sign of disordered brain func tion.

On the other hand, Bainton and Mitchell (1965) reported that post-hyperventilation apnoea occurred in 15 of 16 normal volunteers, after they had become accustomed to the experimental apparatus; Moser et al. (1965) observed the phenomenon in five of 13 , and were able to increase its incidence either by giving oxygen to breathe or by sedation with pentobarbitone.

There is therefore some discrepancy in the literature. Medical students meanwhile are usually taught that there is normally apnoea after hyperventilation (Keele and Neil, 1971; Selkurt, 1971) and they obediently confirm this in laboratory exercises.

In order both to investigate the occurrence of post-hyperventilation apnoea and to evaluate the claim that the five-breath test is clinically useful, we carried out tests similar to those of Plum et al. (1962) in both normal and brain damaged subjects.

A preliminary report of these results has been 
made to the Physiological Society (Ashbridge et al., 1973).

\section{METHODS}

Two groups of subjects were studied:

Healthy volunteers comprised 50 subjects (age range $10-73$ years) who were university students or staff and their families. Only four were medical students or physiologists.

Abnormal subjects were 50 patients (age range 1176 years) from the neurosurgical wards of the Institute of Neurological Sciences. All had intracranial lesions, but were sufficiently alert to cooperate in the test; most were suffering from head injury, tumour, or recent subarachnoid haemorrhage.

RECORDING OF RESPIRATION AND END-TIDAL $\mathrm{CO}_{2}$ CONCENTRATION The subjects breathed through a mouthpiece or well-fitting face mask (Pressure Demand Mask, RAF); either was connected by a low resistance valve box to a flow head on the inspiratory side, so that inspired tidal volume could be measured by pneumotachograph and integrator (Computing Spirometer CS1, Mercury Electronics (Scotland) Ltd). Gas at the mouth was continuously sampled through a rapid infra-red $\mathrm{CO}_{2}$ analyser (URAS 4, Hartmann and Braun). Tidal volume and $\mathrm{CO}_{2}$ concentration were continuously recorded on two channels of an ultraviolet (S.E.L.) or ink-jet (Mingograf) recorder.

To see whether the presence of a mouthpiece or mask, or the click of the valve made any difference to the results obtained, an additional preliminary test was carried out in 20 of the subjects (10 normal subjects, 10 patients) recording only transthoracic impedance. In these instances two disposable electrocardiograph electrodes were applied to either side of the chest and connected to an apnoea monitor (Air Shields Model 3000) from which a trace of respiratory excursion was recorded (North and Jennett, 1972).

PROCEDURE When impedance pneumography only was first recorded, subjects were told that heart rate was to be monitored. For all other tests no explanation was given except to say that routine records of breathing were to be made.

The patients were classified before starting the test, as either alert or drowsy.

Time was allowed for the subject to become accustomed to the apparatus, as assessed by the recorded ventilation and end-tidal $\mathrm{CO}_{2}$ settling to reasonably steady levels. Thereafter, three times during continuous recording, the subject was asked to take five deep breaths; a recovery period of several minutes was allowed between the three tests.

After this routine, 12 of the healthy subjects were asked to overbreathe for 30 seconds as shown by a stop clock placed in front of them; at the end of this period the clock was turned away while recording was continued without comment.

PROCESSING OF DATA Definition of apnoea Even between normal subjects there is considerable variation in frequency of breathing and it was necessary to make allowance both for these differences and also for the irregularities which were common in the breathing pattern of brain damaged patients. Six seconds between breaths would be a normal interval for a subject with a resting frequency of 10 breaths per minute, but would be an apnoeic pause for a

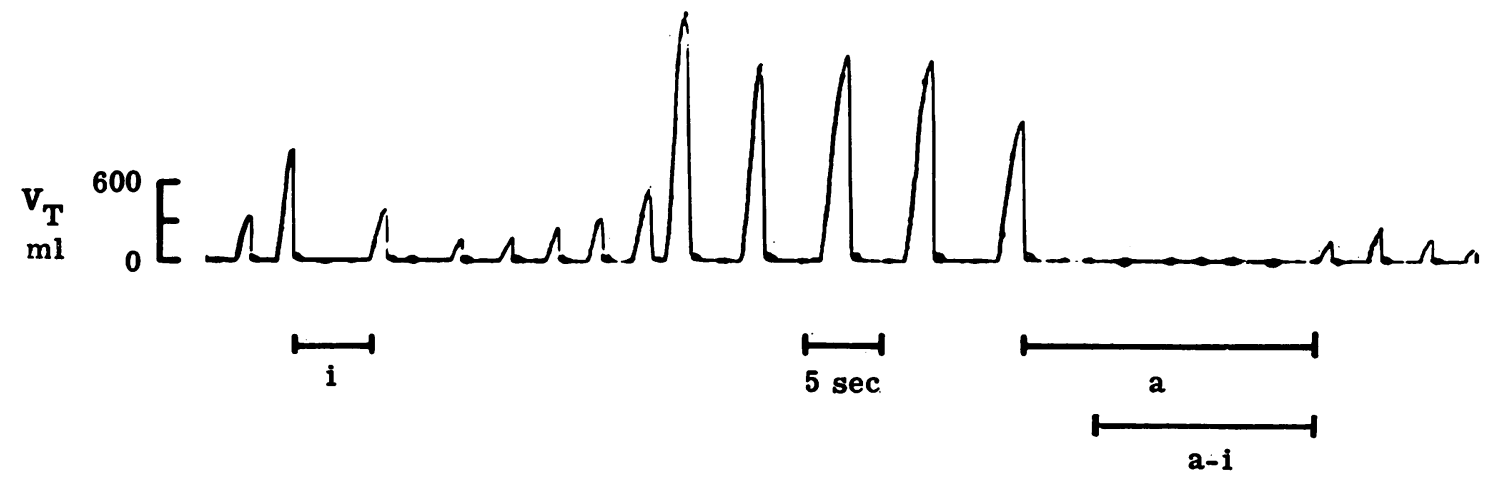

FIG. 1. Inspired tidal volume during a five-breath test in a patient with irregular breathing. i: Duration of longest inter-breath interval in pre-test period. a: Duration of apnoea. a-i: The index of apnoea used in all subsequent data. 


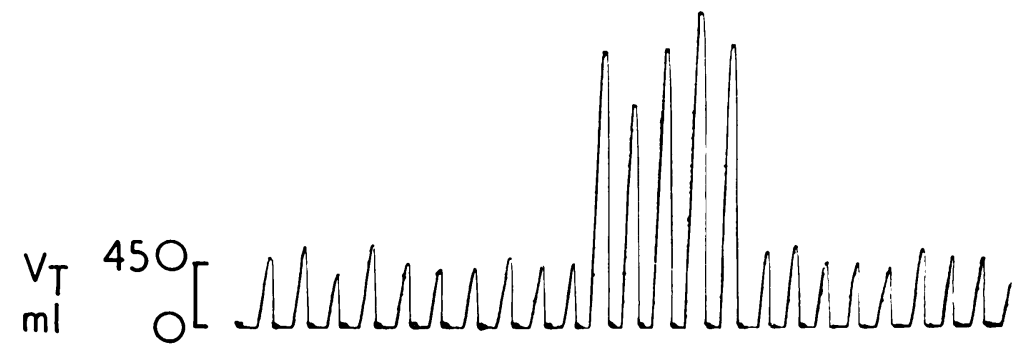

FIG. 2. Typical five-breath test in a healthy subject. Top trace: tidal volume. Lower trace: $\mathrm{CO}_{2}$ concentration at the mouth.
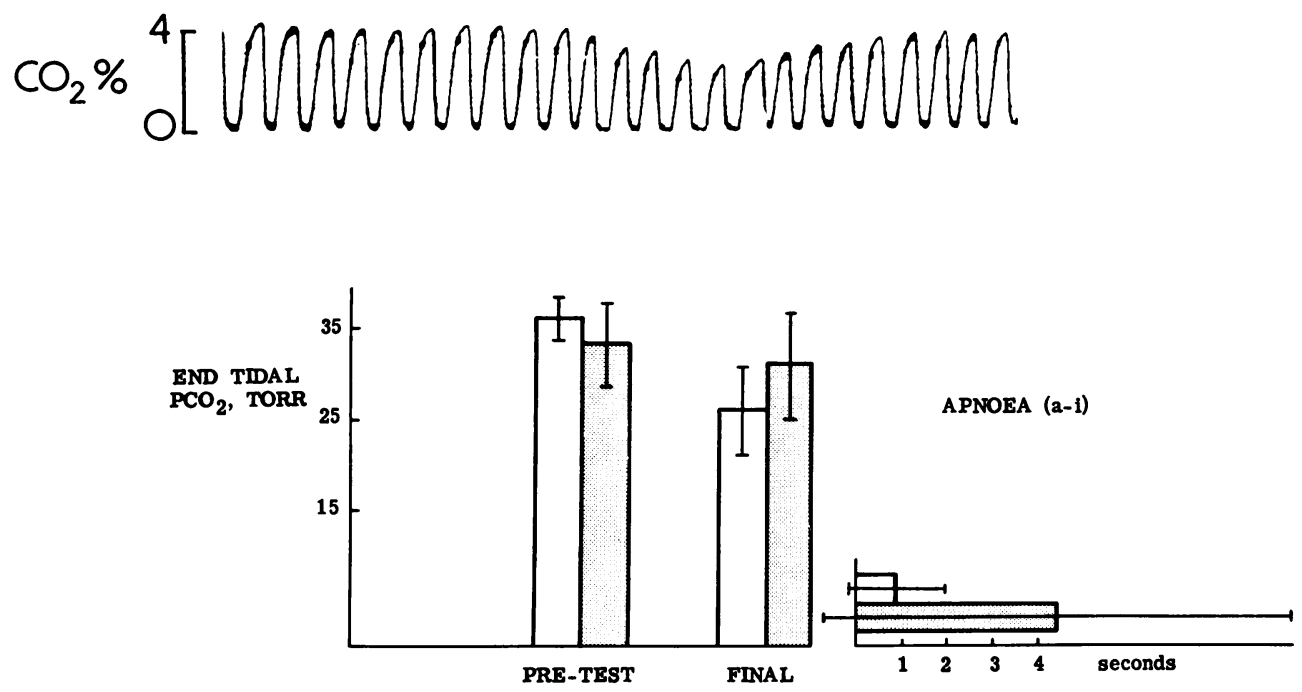

FIG. 3. Comparison between mean results for normal subjects and for patients. Pre-test $\mathrm{PCO}_{2}$ represents mean values during the minute preceding the test. Final $\mathrm{PCO}_{2}$ is the endtidal value for the last breath of hyperventilation. Apnoea is expressed as a-i (see Fig. 1). White columns: 50 normal subjects. Shaded columns: 50 patients with brain damage. Mean values $\pm 1 S D$.

patient who was breathing at 20 per minute. It seemed appropriate to relate the duration of the interval after hyperventilation to the inter-breath intervals occurring during undisturbed breathing before the test. The time interval between the end of the final inspiration of hyperventilation and the beginning of the subsequent inspiration was measured (a, Fig. 1) and was compared with the longest inter-breath interval (i, Fig. 1) observed in the one minute of undisturbed and settled breathing preceding the test. If a exceeded $i$, the subject was regarded as showing post-hyperventilation apnoea, and it was measured as (a-i). Duration of apnoea in succeeding Figures and Tables refers to this index: the duration of cessation of respiration in excess of the longest inter-breath interval for that subject during the minute before that test. Negative values are treated as zero. Thus, for a frequency of breathing of 12-15 per minute, apnoea of 7-8 sec by our definition would be equivalent to about $12 \mathrm{sec}$ as reported by authors such as Plum et al. (1962).

Changes in $\mathrm{PCO}_{2}$ For each test in each subject, the mean end-tidal $\mathrm{PCO}_{2}$ was found from the trace for the minute preceding the test. The end-tidal value for the final breath of hyperventilation was also measured, and the difference between these two values taken as the reduction in alveolar $\mathrm{PCO}_{2}\left(\mathrm{P}_{\mathrm{A}} \mathrm{CO}_{2}\right)$ produced by the ventilatory effort in that test. For each test, the change in $\mathrm{P}_{\mathrm{A}} \mathrm{CO}_{2}$ and also the value to which it was reduced, were plotted against the duration of apnoea (a-i) (see Figs 4 and 5 below). 


\section{RESULTS}

In healthy subjects, apnoea was seldom seen; when present it never exceeded $10 \mathrm{sec}(\mathrm{a}-\mathrm{i})$ and exceeded $5 \mathrm{sec}$ in only four instances out of the total of 172 tests, comprising 150 standard fivebreath tests, 10 using impedance pneumography, and 12 tests of $30 \mathrm{sec}$ hyperventilation. A typical trace is shown in Fig. 2.

In the standard test, these subjects reduced their end-tidal $\mathrm{PCO}_{2}$ by an average of $7 \cdot 3$ torr (SEM 0.3) to an average of 26.5 torr. With 30 sec overbreathing the average reduction was by 9.6 torr (SEM 0.8); no subject showed a greater tendency to apnoea after this longer test than after the-five breath test. In the patients apnoea was relatively common: 19 of the $50(38 \%)$ showed a pause more than $5 \mathrm{sec}$ longer than their pre-test interval, in one or more of the three tests and $34(68 \%)$ showed some degree of apnoea, by our definition.

The decrease in end-tidal $\mathrm{PCO}_{2}$ was very variable between patients, and sometimes between

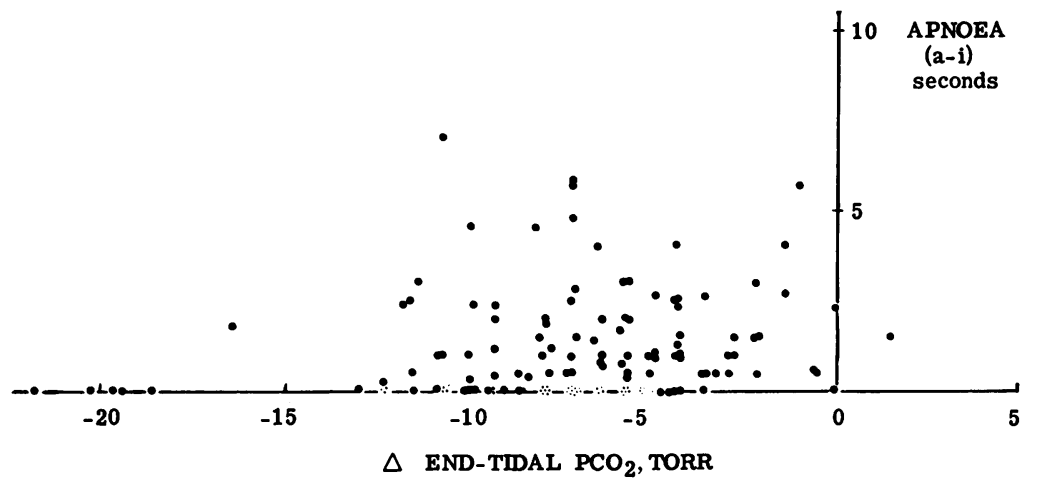

FIG. 4. Duration of apnoea and reduction of end-tidal $\mathrm{PCO}_{2}$ for each of three fivebreath tests in 50 normal subjects. a-i is greater than than 5 sec in only four instances. There is no correlation.

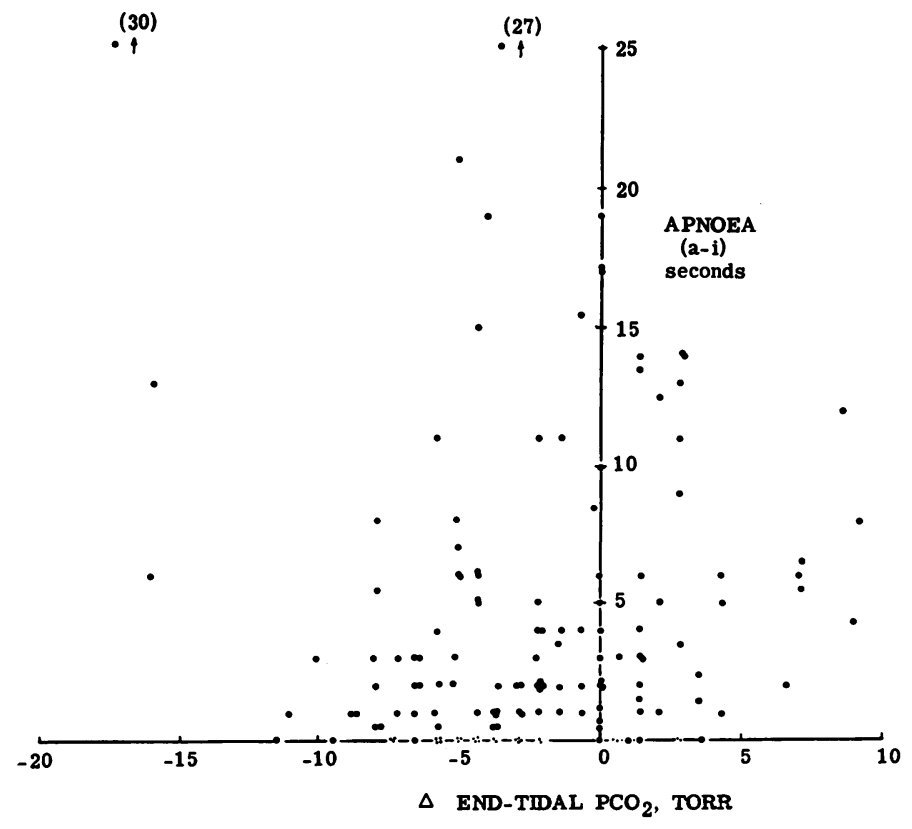

FIG. 5. Duration of apnoea and reduction of end-tidal $\mathrm{PCO}_{2}$ for each of three five-breath tests in 50 patients with brain damage (a-i) is greater than $5 \mathrm{sec}$ in many instances. Points to right of vertical axis represent tests in which end-tidal $\mathrm{PCO}_{2}$ had apparently increased. There is no correlation between apnoea and reduction of $\mathrm{PCO}_{2}$. 


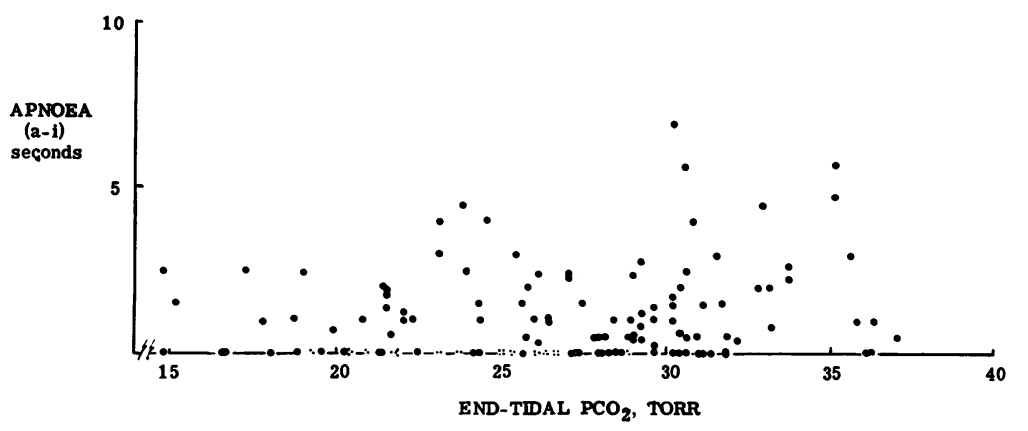

FIG. 6. Duration of apnoea and value of end-tidal $\mathrm{PCO}_{2}$ at the end of the five deep breaths in 50 normal subjects.

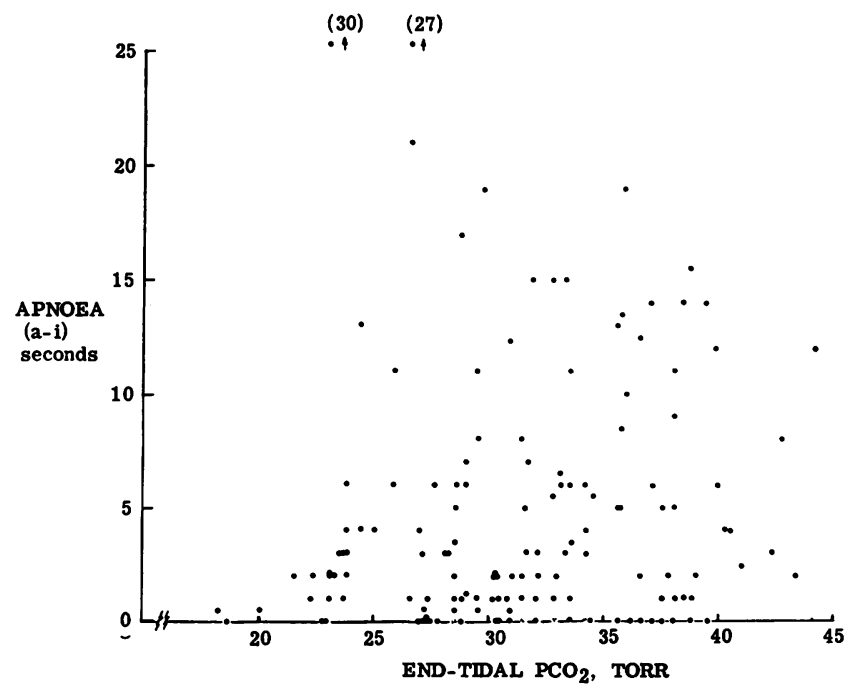

FIG. 7. Duration of apnoea and value of end-tidal $\mathrm{PCO}_{2}$ at end of hyperventilation in 50 patients with brain damage. There is no correlation in either normal or abnormal subjects (see Fig. 6).

tests in any one patient. The mean decrease was only 2.4 torr (SEM 0.3 ), which was significantly smaller than the mean decrease in the healthy subjects; but the mean end-tidal $\mathrm{PCO}_{2}$ at the end of the last breath of hyperventilation (31.3 torr) was not significantly different from that in the healthy subjects because the patients started on average from a lower baseline $\mathrm{PCO}_{2}$ (Fig. 3).

No discrepancy occurred in any individual between the results of tests in which impedance recording only was used and those in which they breathed through the mouthpiece or mask.

RELATIONSHIP BETWEEN POST-HYPERVENTILATION APNOEA AND END-TIDAL $\mathrm{PCO}_{2}$ The plots of reduction in $\mathrm{PCO}_{2}$ against duration of apnoea (a-i) showed no correlation for healthy subjects (Fig. 4) or for patients (Fig. 5).
However, the reduction in $\mathrm{PCO}_{2}$ might be less relevant to the occurrence of apnoea than the absolute level attained; this final level was plotted for each test against duration of apnoea. Again no correlation was shown in healthy subjects (Fig. 6) or in patients (Fig. 7).

RELATIONSHIP BETWEEN POST-HYPERVENTILATION APNOEA AND NEUROLOGICAL DISORDER The 50 patients were divided into two categories according to whether the neurological disorder was unilateral or bilateral, for the purpose of comparison with Plum's series (Plum et al., 1962). This classification was based on physical signs, carotid angiograms, and brain scans; patients with raised intracranial pressure were included in the bilateral group. Table 1 relates these categories 
to the duration of apnoea and shows that no association was found.

RELATIONSHIP BETWEEN POST-HYPERVENTILATION APNOEA AND STATE OF CONSCIOUSNESS Table 2 relates the categories of conscious level, as determined immediately before the tests, to the duration of apnoea. The association between the drowsy state and apnoea was significant. Of 21 patients who had been allocated to the drowsy category, $20(95 \%)$ showed apnoea in at least one of the three tests, and this was longer than $10 \mathrm{sec}$ (a-i) in 10 of the patients. Of the 29 patients classified as alert, apnoea occurred in only 14 $(49 \%)$.

TABLE 1

RELATIONSHIP TO APNOEA OF TWO CATEGORIES OF PATIENT

\begin{tabular}{lccccc}
\hline \multirow{2}{*}{ Brain lesion } & \multicolumn{4}{c}{ Apnoea $(a-i)$} \\
\cline { 2 - 6 } & Present & \multicolumn{4}{c}{ Duration $(\mathrm{sec})$} \\
\cline { 3 - 6 } & & 10 & $5-10$ & 5 \\
\hline Unilateral (30 patients) & $20(67 \%)$ & 7 & 7 & 6 \\
Bilateral (20 patients) & $14(70 \%)$ & 4 & 1 & 9 \\
\hline Totals (50 patients) & $34(68 \%)$ & 11 & 8 & 15 \\
\hline
\end{tabular}

Difference between categories not significant.

TABLE 2

LEVEL OF CONSCIOUSNESS RELATED TO APNOEA

\begin{tabular}{lcccc}
\hline & \multicolumn{4}{c}{ Apnoea $(a-i)$} \\
\cline { 2 - 5 } Level of consciousness & Present & \multicolumn{4}{c}{ Duration (sec) } \\
\cline { 3 - 5 } & & $>10$ & $5-10$ & $<5$ \\
\hline Alert (29 patients) & $14(48 \%)$ & 1 & 1 & 12 \\
Drowsy (21 patients) & $20(95 \%)$ & 10 & 7 & 3 \\
\hline Totals (50 patients) & $34(68 \%)$ & 11 & 8 & 15 \\
\hline
\end{tabular}

Difference between categories significant $(P<0.001)$.

\section{DISCUSSION}

SUBJECTIVE FACTORS The validity of the results of these studies depends to a great extent on the attitude of the subjects and on the way in which they were told what was required of them. Few knew what might be expected in terms of the classical description of post-hyperventilation apnoea. The only instruction given to the subject was to take the five deep breaths: this was said as casually as possible, implying that it was incidental and not the main object of the exercise. No further instruction was given after the deep breaths were completed.

The method involved apparatus which inevitably drew the subject's attention to their breathing, and it could be argued that such awareness would tend to make them continue to breathe regularly. By this theory, the occurrence of apnoea in the drowsy subjects could be explained as a lack of attention. However, this explanation was excluded by the similarity of results when only impedance pneumography was used. It must nevertheless be admitted that, whatever the apparatus or the observer's apparent lack of interest in the subject's breathing, it is impossible to prevent attention being drawn to breathing by requesting the subject to make a ventilatory effort; alert subjects may perhaps obligingly continue.

Plum et al. (1962) recorded respiratory pattern by pneumograph and took pains to distract the attention of the subjects during the test. Despite the difference in our approach and in our apparatus it is of interest that the difference in the incidence of apnoea between normal and abnormal subjects in our two series was similar.

CHANGES IN $\mathrm{PCO}_{2}$ It was an unexpected feature of our results that, when apnoea occurred after hyperventilation, it was unrelated to the actual lowering of end-tidal $\mathrm{PCO}_{2}$. Plum et al. (1962) did not relate the individual values for change in $\mathrm{PCO}_{2}$, or for absolute levels attained after the five-breath test, to the occurrence and duration of apnoea; they included only those tests in which a reduction of at least 6 torr was obtained. They would thereby have excluded most of the tests on our patients. In doing this, they reasonably presupposed that a certain reduction in chemical drive was necessary to cause apnoea. In view of our findings, the phenomenon in the abnormal subjects might be better described as apnoea after ventilatory effort, rather than after hyperventilation, since in many instances there 


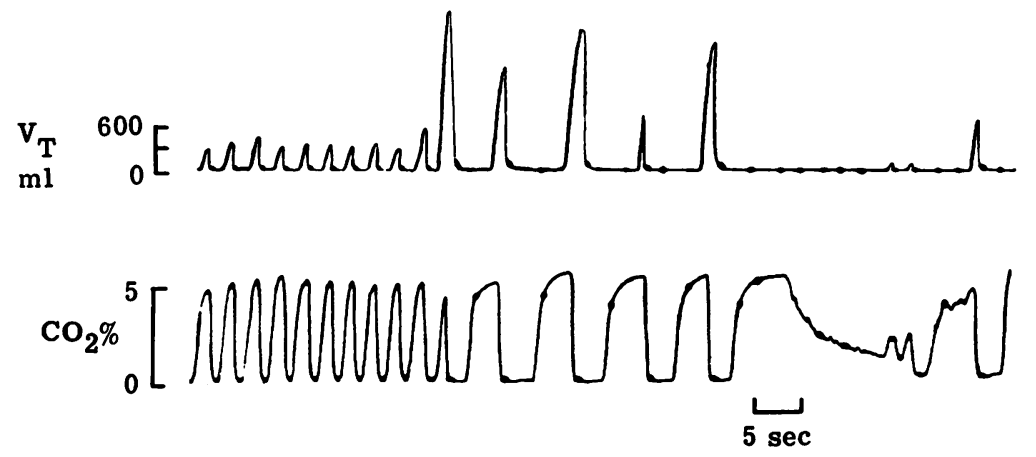

FIG. 8. Example of a test during which the end-tidal $\mathrm{PCO}_{2}$ was not reduced, yet apnoea occurred.

was no measurable hyperventilation as defined by a reduction in $\mathrm{PCO}_{2}$.

The end-tidal values were taken to be an estimate of alveolar $\mathrm{PCO}_{2}$, and this in turn of arterial $\mathrm{PCO}_{2}$. If any of the subjects had abnormalities of gas exchange, the arterial $\mathrm{PCO}_{2}$ might have been higher than the end-tidal. Also endtidal values may have been misleadingly low when tidal volume was small and frequency high, so that an alveolar plateau was not reached; if this were so in the period preceding the test, the deeper slower breaths of the ventilatory effort might give a more valid alveolar plateau value, and explain the apparent lack of reduction (or even apparent increase) in $\mathrm{PCO}_{2}$ in some cases. However, this could not explain many of the instances where apnoea followed a five-breath test which had brought about no reduction in the end-tidal level: the alveolar ventilation must be assumed to have remained constant despite the altered pattern of breathing (Fig. 8).

RELATIONSHIP BETWEEN ALVEOLAR AND BRAIN TISSUE $\mathrm{PCO}_{2}$. Haldane and Priestley (1905) thought that it was possible for the central $\mathrm{PCO}_{2}$ to change rapidly enough after a deep breath to delay the next breath. Several later studies have shown that the latency between a change in alveolar gas tension and an alteration in ventilation attributable to a central effect is much longer - of the order of 10-20 sec (Bülow, 1963; Lambertsen et al., 1965). Even an effect acting via the peripheral chemoreceptors is delayed until the third or fourth breath after such a change (Dejours et al., 1958). Also it is now held that the medullary chemoreceptors (Mitchell et al., 1963) are influenced not only by changes in arterial $\mathrm{PCO}_{2}$ but also by the $\mathrm{pH}$ of the cerebrospinal fluid. This means that the full effect of a change in arterial $\mathrm{PCO}_{2}$ would be delayed even longer (Lambertsen et al., 1965).

The value of the end-tidal $\mathrm{PCO}_{2}$ at the final breath of the ventilatory effort in the five-breath test would therefore not be a valid indication of the reduction in central respiratory drive at this time: the value at the medullary chemoreceptor $\bar{D}$ would be higher. The values plotted in Figs 6 and 7 are therefore likely to be several torr loweb than those affecting the medulla. If end-tidas $\mathrm{PCO}_{2}$ were in some cases less than arterial $\mathrm{PCO}_{2}$ the underestimation of the 'central drive' would be even greater. It seems unlikely, therefore, that the five-breath test results in a sub-threshold value of $\mathrm{PCO}_{2}$ centrally, unless perhaps that threshold is higher than normal-as in some patients with Cheyne-Stokes respiration (Brown and Plum, 1961).

It has usually been assumed that the occurrence and duration of apnoea is quantitatively related to the reduction in arterial $\mathrm{PCO}_{2}$, but the complete lack of correlation in our results suggests that reduction in chemical drive is not the essential factor leading to apnoea after ventilatory effort in patients with brain damage.

These arguments raise the possibility that a longer hyperventilation, by undoubtedly lowering the $\mathrm{PCO}_{2}$ to a sub-threshold level in the environment of the medullary chemoreceptors, might produce different results.

We carried out a subsidiary study on 12 healthy subjects using similar apparatus and procedure, but asking them to overbreathe for a full two 

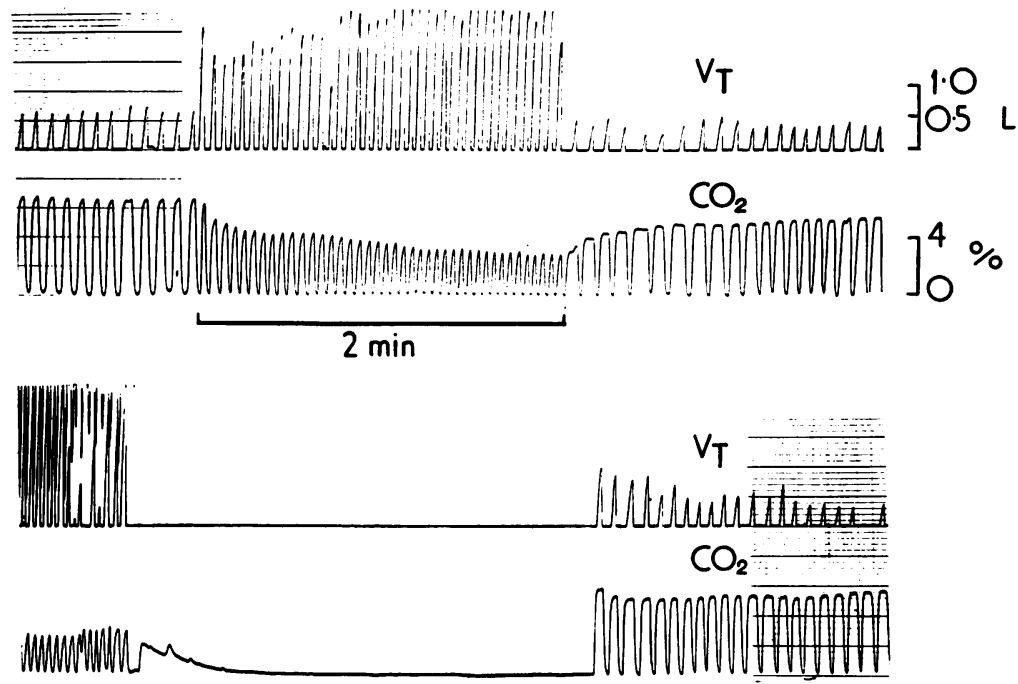

FIG. 9. The effect of two minute hyperventilation in a normal subject. Top two traces: tidal volume and endtidal $\mathrm{CO}_{2}$ during test when the subject was asked to overbreathe for two minutes and given no further instruction. This was typical of such a test in 12 subjects. Lower traces: tidal volume and end-tidal $\mathrm{CO}_{2}$ at the end of a second period of two minutes hyperventilation in the same subject, and the apnoea which followed when it was suggested that he need not continue to breathe. minutes. They reduced their end-tidal $\mathrm{PCO}_{2}$ by a mean of 17 torr to a mean of 22.9 torr, and in most the reduction was virtually complete by the end of the first minute. At the end of the hyperventilation only two showed an interval longer than the spontaneous inter-breath intervals, and the longer of these was only $9 \mathrm{sec}$. All showed a gradual return to normal end-tidal $\mathrm{PCO}_{2}$ over three to four minutes; half of them showed a slight degree of periodicity superimposed on this progressive recovery. These results were consistent with those of Fink (1961) and of Mills (personal communication).

One subject was asked, after the two minute hyperventilation and recovery therefrom, to repeat the exercise, but this time it was suggested that he should not breathe until he felt it to be necessary. The two results are shown in Fig. 9. We feel that this goes a long way towards explaining the results of Douglas and Haldane (1909).

THE WAKEFULNESS FACTOR The present study has reinforced the concept that apnoea does not occur after hyperventilation in the fully awake subject, unless some respiratory activating stimulus is diminished or removed, or unless the possibility of not requiring to breathe has been suggested to him.

We could not show an association between the occurrence of apnoea and those lesions which by other criteria would be classified as bilateral rather than unilateral, but we have by contrast shown an association with alteration in the state of consciousness. This is compatible with the results of Moser et al. (1965) in which the incidence of apnoea after hyperventilation was much increased by a dose of barbiturate. These results suggest that the diagnostic application of the test is limited to an additional criterion of conscious level.

When apnoea followed a ventilatory effort which did not reduce the $\mathrm{PCO}_{2}$, the patients might have been breathing throughout the study at a subthreshold value, because of the general stimulation of the occasion; after the additional effort of the deep breaths, they could have lapsed into inattention until their genuine threshold was reached. However, since many of them were initially classified as drowsy, this seems unlikely.

Alternatively, the increased lung inflation during the ventilatory effort could be implicated as having an inhibitory effect, delaying the resumption of normal rhythm in the abnormal subject. At the end of the last century there was considerable discussion between the proponents of 'vagal apnoea' on the one hand and of 'chemical apnoea' on the other. No one would now doubt that a low $\mathrm{PCO}_{2}$ causes apnoea under conditions where no other drives are maintaining respiratory centre activity. Haldane and Priestley (1905) said that none of the experiments published on apnoea had afforded any proof "that 
the apnoea has not been due to diminution of the $\mathrm{CO}_{2}$.

The apnoea which, in some of our patients, followed ventilatory effort without a measured reduction in $\mathrm{P}_{\mathrm{A}} \mathrm{CO}_{2}$ might possibly be associated with 'afteraction caused by the increase and diminution in the volume of the lungs' (Head, 1889). Their tidal volumes were over 1 l., a degree of inflation which has been shown to inhibit breathing in man (Guz et al., 1964).

Our comments concerning wakefulness and the possible importance of afferent information from the lungs are, however, difficult to reconcile with the recent interesting report (Eldridge, 1973) that in cats there is no apnoea after neurally generated hyperventilation despite anaesthesia and vagotomy.

\section{CONCLUSIONS}

After brief hyperventilation, we have found apnoea to be common in drowsy brain-damaged patients but rare in healthy subjects. The lack of correlation between the length of apnoea and lowering of $\mathrm{P}_{\mathrm{A}} \mathrm{CO}_{2}$ suggests that hypocapnia is of lesser importance than is generally assumed. The strong association between drowsiness and apnoea supports Fink's (1961) hypothesis that normal respiratory rhythm in the wakeful state is due to a non-chemical stimulus. Because of the poor correlation between apnoea and bilateral lesions, we conclude that the test for posthyperventilation apnoea (Plum et al., 1962) is not useful in the recognition of bilateral cerebral dysfunction.

We are grateful to the consultants in the Institute of Neurological Sciences whose patients were involved in the study, and to our healthy volunteers. The work was supported in part by a grant from the Scottish Hospital Endowments Research Trust.

\section{REFERENCES}

Ashbridge, K. M., Jennett, S., and North, J. B. (1973). The absence of post-hyperventilation apnoea in the wakeful state. Journal of Physiology, 230, 52-53P.
Bainton, C. R., and Mitchell, R. A. (1965). Posthyperventilation apnoea in awake man. (Abstract.) Federation Proceedings, 24, 273.

Boothby, W. M. (1912). Absence of apnoea after forced breathing. Journal of Physiology, 45, 328-337.

Brown, H. W., and Plum, F. (1961). The neurologic basis of Cheyne-Stokes respiration. American Journal of Medicine, 30, 849-860.

Bülow, K. (1963). Respiration and wakefulness in man. Acta Physiologica Scandinavica, 59, Suppl. 209.

Dejours, P., Labrousse, Y., Raynaud, J., and Flandrois, R. (1958). Etude du stimulus gaz carbonique de la ventilation chez l'homme. Journal de Physiologie, 50, 239-243.

Douglas, C. G., and Haldane, J. S. (1909). The causes of periodic or Cheyne-Stokes breathing. Journal of Physiology, 38, 401-419.

Eldridge, F. L. (1973). Posthyperventilation breathing: different effects of active and passive hyperventilation. Journal of Applied Physiology, 34, 422-430.

Fink, B. R. (1961). Influence of cerebral activity in wakefulness on regulation of breathing. Journal of Applied Physiology, 16, 15-20.

Guz, A., Noble, M. I. M., Trenchard, D., Cochrane, H. L., and Makey, A. R. (1964). Studies on the vagus nerves in man: their role in respiratory and circulatory control. Clinical Science, 27, 293-304.

Haldane, J. S., and Priestley, J. G. (1905). The regulation of ci the lung-ventilation. Journal of Physiology, 32, 225-266.

Head, H. (1889). On the regulation of respiration. Journal of Physiology, 10, 1-70.

Keele, C. A., and Neil, E. (1971). Samson Wright's Applied Physiology, 12th edn., p. 200. Oxford University Pressł London.

Lambertsen, C. J., Gelfand, R., and Kemp, R. A. (1965 Dynamic response characteristics of several $\mathrm{CO}_{2}$-reactive components of the respiratory control system. In Cerebrespinal Fluid and the Regulation of Ventilation, pp. 211-245. Edited by C. McC. Brooks, F. F. Kao, and B. B. Lloyd. Blackwell: Oxford.

Mills, J. N. (1946). Hyperpnoea induced by forced breathing. Journal of Physiology, 105, 95-116.

Mitchell, R. A., Loeschcke, H. H., Massion, W. H., and Severinghaus, J. W. (1963). Respiratory responses mediated through superficial chemosensitive areas on the medulla. Journal of Applied Physiology, 18, 523-533.

Moser, K. M., Rhodes, P. G., and Kwaan, P. L. (1965). Posthyperventilation apnea. (Abstract.) Federation Proceedings, 24, 273.

North, J. B., and Jennett, S. (1972). Impedance pneumography for the detection of abnormal breathing patterns associated with brain damage. Lancet, 2, 212-213.

Plum, F., Brown, H. W., and Snoep, E. (1962). Neurologic 3 significance of posthyperventilation apnea. Journal of the American Medical Association, 181, 1050-1055.

Selkurt, E. E. (1971). Physiology, 3rd edn. Little, Brown: Boston. 